\title{
Adsorption Isotherms and Thermodynamic Data for Removal Pesticides from Aqueous Solution on Pomegranate Peel Surface
}

\author{
Nada Ehya Fairooz ${ }^{1}$, Zainab Abbas Jwad ${ }^{1}$, Mohammed Alaa Abdul Zahra ${ }^{2}$ \\ ${ }^{1}$ Chemistry Department, Babylon University, Hilla, Iraq \\ ${ }^{2}$ Chemistry Department, College of Education for Pure Sciences, Karbala University, Karbalaa, Iraq
}

Email address:

Fairoz.nada@yahoo.com (N. E. Fairooz), the_zlight2@yahoo.com (Z. A. Jwad), Organicmohammed@gmail.com (M. A. A. Zahra)

To cite this article:

Nada Ehya Fairooz, Zainab Abbas Jwad, Mohammed Alaa Abdul Zahra. Adsorption Isotherms and Thermodynamic Data for Removal Pesticides from Aqueous Solution on Pomegranate Peel Surface. American Journal of Applied Chemistry. Vol. 3, No. 4, 2015 , pp. 147-152. doi: 10.11648/j.ajac.20150304.11

\begin{abstract}
This work includes the study of the ability of pomegranate peel as adsorbent for two kinds of pesticides (Lambda cyhalothrin and Diazinon) from their aqueous solutions. The equilibrium contact time for the samples was determined. The effect of some factors on the adsorption process which was represented by the effect of acidity function was also studied. It was found that the best adsorption is at $\mathrm{pH}=2$. The effects of the different temperatures within the range $(313,323$, and $333 \mathrm{~K})$ were studied. The amount of adsorption for the pesticides is decreased with the increase of temperature; this indicates that the adsorption process is exothermic. Finally the study of the adsorption isotherms takes the (S-shape) according to Gile's classification for all the cases from (S2, S4) type which is following the freundlich equation for the adsorption.
\end{abstract}

Keywords: Adsorption, Pesticides, Freundlich Equation, Gile's Classification

\section{Introduction}

Industrial wastewaters largely possess organic and lnorganic materials such as pesticides, dyes, phenolic compounds, aromatic compounds and heavy metals [1].

Recently, a number of research works have been performed for the synthesis of conducting composites that contain a natural polymer [24]. Along this, nonocomposites of PANI with starch and chitosan have been studied on the basis of their biocompatility, antioxidant activity, and potential removal of reactive dyes and heavy metal ions.

Water is one of the vital necessities for the survival of human beings, the water demand doubles globally every 21 years due to the rapid increase in rainfall in the previous decade [2]. Most of the currently available technologies are inadequate for the removal of pesticides and color-induced toxic pollutants such as dyes from textile waste water [3]. Most of the conventional methods of wastewater treatment are such as coagulation and flocculation. Sedimentation and floatation, membrane filtration, disinfection is either expensive or not very effective.

Adsorption is a convenient separation process, in which the adsorbent may be of organic, mineral or natural source. (Wan
Ngah, Teong \& Hanafiah, 2010). Various materials such as zeolites, activated carbon, clays, agricultural wastes, biomass and synthetic polymers were used as an adsorbent (Karami, 2013; Tirtom, Dincer, Becerik, Aydemir\& Celik, 2012).

These technologies mostly transform pollutants from one phase to another and do not completely eliminate them [4].

Adsorption has been recognized as a potential technology for the removal of pesticides, dyes and other pollutants from waste water. In comparison to other physical, chemical and biological methods available for the treatment of wastewater, adsorption is the most preferred technique due to simple and flexible design and easy operation. The adsorption process may generate little or no toxic pollutants and involve low initial capital and operating costs [5-7]. Adsorption can be classified as either physical or chemical physical adsorption (physisorption ) involves weak for gas and is therefore reversible, it occur at low tem partners. It is very similar to a condensation process and thus it is exothermic with a heat of adsorption similar to that latent heat of condensation [8]. Chemical adsorption (chemisorption) it is important in gas phase catalysis, and it is occur at high temperatures with significant activation energy involves strong bonds and is not reversible different isotherms of adsorption from solution on 
solid active surface which were classified by Giles [9-11].

The aim of this work was to prepare some novel pomegranate peel adsorbents and to study the adsorption capacity of these adsorbents for two pesticides removal from aqueous solutions. Adsorption isotherms and kinetics were investigated and different adsorption models were used to evaluate the experimental data and to elucidate the possible adsorption mechanism. Thermodynamic studies were also carried out to estimate the standard free energy $\left(\Delta G^{\circ}\right)$, enthalpy change $\left(\Delta H^{\circ}\right)$ and entropy change $\left(\Delta S^{\circ}\right)$. These funddamenta data will be useful for further applications in the treatment of practical waste or process effluents.

\section{Experimental Part}

\subsection{Apparatus}

1- U.V. - visible T604 spectrophotometer PQ instruments LTd.

2- Laborator oven memmort/w. Germany.

3- Electronic Balance Sartorius, w. Germany.

4- HANNA, pH-meter, Instrument, Portngal.

5- Shaking Indicator. GCA. / Precision scientific Chicago. U.S.A.

6- Distilled- water Apparatus within the type Gel (Gasell schaft fur Labortechnik) Mbh, w. Germany.

\subsection{Chemicals}

All chemicals used in the present work were used without further purification.

Table (1). purification values for chemicals were used in this work.

\begin{tabular}{llll}
\hline No. & Chemicals & Company & Purity\% \\
\hline 1 & Lambda cyhalothrin & B.D.H & $90 \%$ \\
2 & Dizinon & B.D.H & $90 \%$ \\
3 & Pomegranate peel & From nature & \\
4 & Sodium hydroxide & B.D.H & $98 \%$ \\
5 & Hydrochloric Acid & B.D.H & $(36.5 \%)$ \\
\hline
\end{tabular}

\subsection{Preparation of Solutions}

All pesticides solutions are used in this work were prepared by dissolving $0.01 \mathrm{gm}$ in $200 \mathrm{ml}$ volumetric flask with distilled water to prepare the concentration $(500 \mathrm{ppm})$ as stock solution and prepare a series of different concentrations in the range (2-20 ppm) from the stock solution by dilution law.

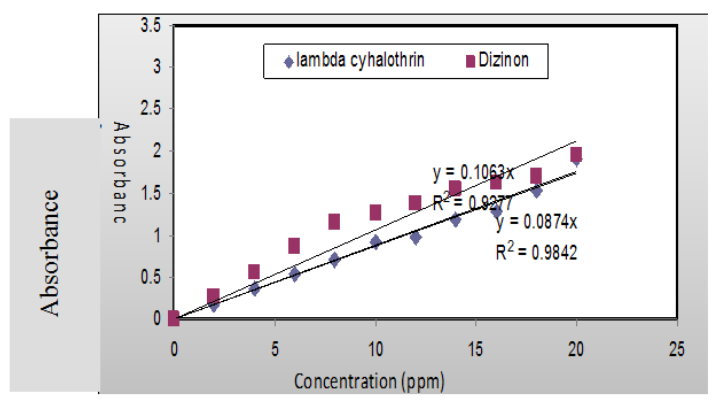

Figure (1). Calibration curve for adsorption the compounds on pomegranate peel at $313 \mathrm{~K}$.
Determination of $\lambda \max$ and calibration curves for the pesticides (lambda cyhalothrin and Diazinon).

The maximum wavelength of each pesticide was specified by using spectrophotometer in the range of $(200-800 \mathrm{~nm})$ and recording the spectra of absorption as shown in figure 1 and table 2 .

Table (2). values of $\lambda$ max for the pesticides were used in this work.

\begin{tabular}{lll}
\hline \multirow{2}{*}{ Pesticides } & $\boldsymbol{\lambda}$ Max $/ \mathbf{n m}$ & \\
\cline { 2 - 3 } & Literature & Observed \\
\hline Lambda cyhalothrin & 217 & 222 \\
Diazinon & 218 & 220 \\
\hline
\end{tabular}

\subsection{Adsorption Studies}

The adsorption experiments were studied in aqueous solution, using a constant weight adsorbent surface $(0.2 \mathrm{gm})$ immersed in (15) $\mathrm{ml}$ aqueous solutions (20mgL-1) of pesticides. The mixtures were agitated at 5000rprm at room temperature for different contact times then the adsorbent surface was separated by filtration and the filtrate was analzed uv-visible spectrop-hotometer at wavelength corrws -ponding to the $\lambda$ max of each pesticide. The PH values of the initial solutions were fixed using IM NaOH or $(1 \mathrm{~m}) \mathrm{HCL}$ solutions and PH meter (HANNA, PH, meter, Instrument, Portnyal was employed for $\mathrm{PH}$ measurements. The equilibrium time for adsorption of lambdacyha lothrin pesticide was much longer (120 min) than that for Diazinon (30 $\mathrm{min})$ the results wew demonstrated that the tendency adsorbent surface for removed of lambdacyhalothrin much more than that for diazinon pesticide in fact due to diffuse in composite matrix easier than diazinon that is accessible coordinating sites become excluded after equilibrium state [12].

\subsubsection{Preparation of Pomegrante Peel (pp)}

Raw pomegrant peel was selected and washed with water several times to remove ash and other contaminants. Then it was washed with double distilled water and was dried at $70^{\circ} \mathrm{c}$ indside convection over for $24 \mathrm{~h}$. The dried Pomegrante peel was crushed and sieved to be a smaller particle by a 50 meshsieve. The obtained product was named $p p$ for further adsorption study.

\subsubsection{Adsorption Isotherms}

Batch adsorption experiments were conducted using $50 \mathrm{ml}$ stoppered conicalflasks at room temperature $\left(25^{\circ} \mathrm{c}\right)$ twenty $\mathrm{mg}$ of adsorbent was added to each flask which consisted of $10 \mathrm{ml}$ pesticides solution of various initial concentrations from [two pestieides]. All flasks were shaken at 5000rpm in a thermostated shaker for (120min). After decantation and filtration, the pesticides concentration in the filtration solution was analyzed by using UV-visible spectrophotometer the amount of pesticides adsorbed was calculated from the following equation.

$$
Q e=\frac{V_{s o l}\left(C_{0}-C_{e}\right)}{m}=\frac{x}{m}
$$


Where $\mathrm{Qe}=\mathrm{x} / \mathrm{m}$ the quantity of adrobed material $(\mathrm{mg}) / \mathrm{g}$ adsorbent

$\mathrm{V}=$ volume of pesticide solution $(\mathrm{L})$ that was used

$\mathrm{C} 0=$ Initial concentration $(\mathrm{mg} / \mathrm{L})$

$\mathrm{Ce}=$ Equilibrium concentration $(\mathrm{mg} / \mathrm{L})$

$\mathrm{m}=$ weight of adsorbent $(\mathrm{g})$

The amount of adsorption is expressed by the ratio $\mathrm{x} / \mathrm{m}$ which is defined as the quantity of adsorbate in $(\mathrm{mg})$ held by weight of adsorbent ( $\mathrm{g})$.

$$
\text { Removal\% }=[(\mathrm{C} 0-\mathrm{Ce}) / \mathrm{C} 0] \times 100
$$

[13].

\subsection{Factors influencing Adsorption Process}

(A) * Effect of Adsorbent weight

The effect of adsorbent weight on the adsorption was studied by using $15 \mathrm{ml}$ of $20 \mathrm{ppm}$ from each pesticide with different weigh of adsorption $(0.05,0.1,0.2 .0 .3 .0 .4 .0 .5 \mathrm{gm})$ at $313 \mathrm{~K}$ for suitable time. The maximum adsorption weight for lambda cyhalothrim was $(0.2 \mathrm{gm})$ while $0.05 \mathrm{gm}$ for Diazinon. With a molecule size of $212 \mathrm{~nm}$ by suitable sieving.

(B) Effect of $\mathrm{pH}$

Adsorption experiments were carried out as a function of $\mathrm{pH}$ by using $15 \mathrm{ml}$ of $20 \mathrm{ppm}$ solution from each pesticide in different $\mathrm{pH}$ - media. $\mathrm{NaOH}(0.1 \mathrm{~N})$ and $(0.1 \mathrm{~N}) \mathrm{HCL}$ were used to adjust the $\mathrm{pH}$ in the range $(2-12)$ and at $313 \mathrm{~K}$. the concentration of the adsorbent was measured by UV-visible spectrophotometer.

(c) Effect of Temperature

Adsorption process were performed in the same manner as mentioned in the above paragraph at temperature $(313,323$, $333 \mathrm{~K}$ ) to estimate the thermodynamic behavior of adsorption process, this depends if the adsorption decreases with increasing temperature then the process is exothermic and vice versa.

\section{Results and Discussion}

* Adsorption ability on surface of pomegranate peel Figure (2) represents the adsorption Isotherms for the two Pesticides

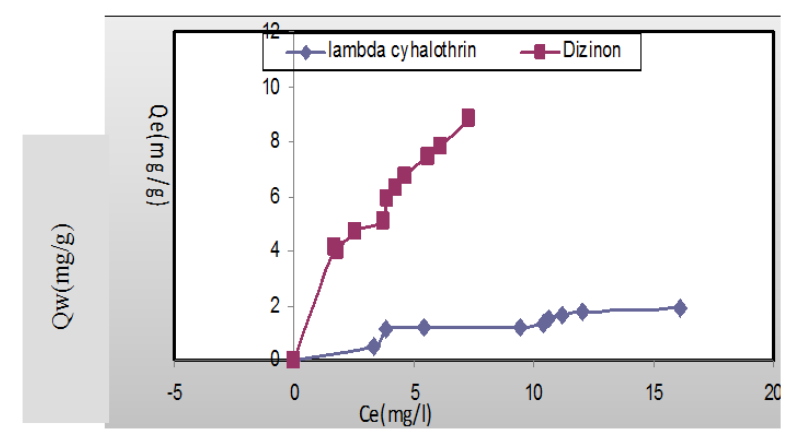

Figure (2). Shows the Isotherms adsorption on pomegrante surface for the two pesticides.

The equilibrium adsorption data were analyzed using
Langmuir and freundlich adsorption isotherm models $[14,15]$,as in figures 3 and 4 respectively.

The pesticides are organic compounds in nature with functional groups either drawing or pumping electrons which are very effected on the adsorption processes, so the pesticiedes with electrons pumping groups will be increase the adsorption process while groups with drawing electrons will be decrease the adsorption isaotherm [16].

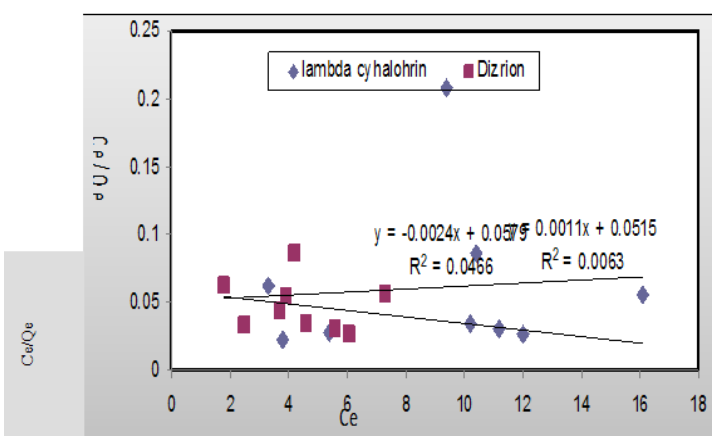

Figure (3). The Langmuir isotherms for the two pesticides on the pomegrante peel surface.

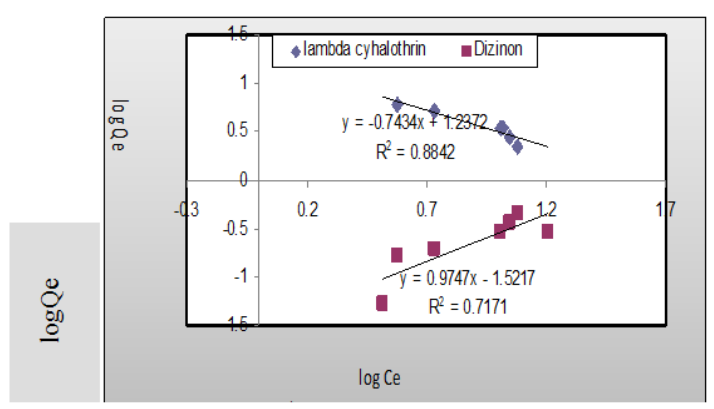

Figure (4). Freundlinch isotherms for adsorption on the pomegrante peel surface.

According to Gile's classification the data obtained in this research are followed the type (S2, S4). Also the maximum adsorption time was 30 minute for diazinon and120 minute for lambda cyhatothrin as shown in figure (5) at $313 \mathrm{~K}$ and the maximum weight for the adsorption was $0.2 \mathrm{~g}$ diazinon and $0.05 \mathrm{~g}$ cyhatothrin as in figure (6) and were studied the freundhich and Langmuir constants for adsorption process as well as in table 2 [20-21].

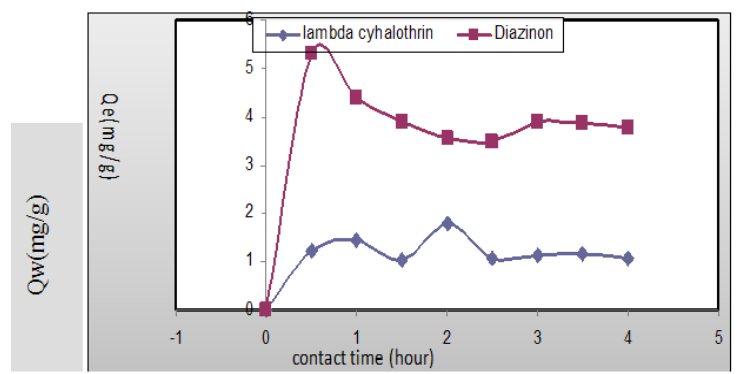

Figure (5). The effect of contact time on the surface for adsorption isotherms of the two pesticides. 


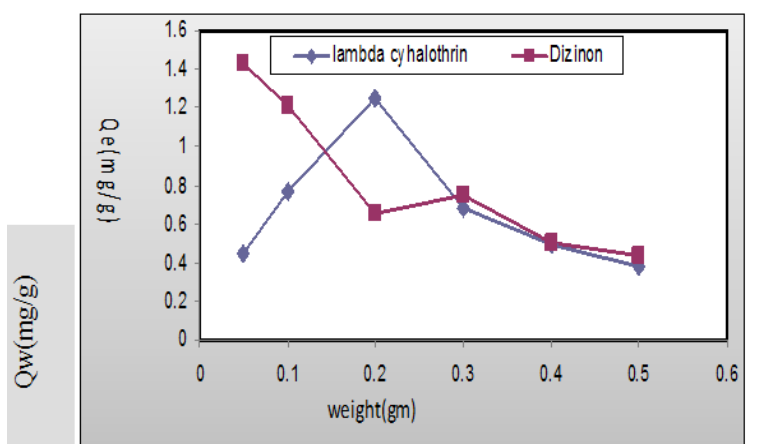

Figure (6). The effect of weight of adsorbent on the isotherm of the two pesticides Gap not given.

Table (3). Frendlinch and Langmuir constants for adsorption the two pesticides at $313 k$.

\begin{tabular}{lllllll}
\hline Pesticides & Kf & $\mathbf{n}$ & $\mathbf{R 2}$ & $\mathbf{a}$ & $\mathbf{k}$ & $\mathbf{R 2}$ \\
\hline $\begin{array}{l}\text { Iambda } \\
\text { cyhalothrin }\end{array}$ & 17.26 & -1.344 & 0.884 & 0.001 & 19.61 & 0.006 \\
Diazinon & 0.030 & 1.027 & 0.717 & 0.002 & 17.54 & 0.001 \\
\hline
\end{tabular}

Two isotherms equations have been tested in the present study to analyze the equilibrium data of (PP) and (PP) namely, Langmuir, Freundich. The results are shown in table 2 and the modeled isotherms are plotted Fig (3-4).

Based on the assumption that all adsorption sites are equivalent and adsorption in active sites is indepent of whether the adjacent is occupied, the Langmuir adsorption model can be expressed as :

$$
\frac{C_{e}}{q_{e}}=\frac{1}{q_{1} K_{1}}+\frac{1}{q_{L}} C e
$$

Where $q_{e}$ is the mono-layer adsorption capacity adsorbent $(\mathrm{mg} / \mathrm{g}), K_{1}$ is the Langmuir adsorption constant $(\mathrm{L} / \mathrm{mg})$ and $q_{L}$ is the mono-layer adsorption capacity of adsorbent (mg/g). Therefore, a plot of $\mathrm{Ce} / q_{e}$ versus Ce gives a straight line of slope $1 / q_{L}$ and intercepts $1 /\left(q_{L} K_{L}\right)$.

From table 2 the correlation coefficients of broth (PP) and $\mathrm{KOP}$ are very high, indicating a good fit of the mono - layer langmuir to the adsorption of (PP).the mono- layer adsorption capacity .

The Freundlich model can be expressed as [25] :

$$
\log q_{e}=\log k_{F}+\frac{1}{n} \log C_{e}
$$

Wher KF and $\mathrm{n}$ are the Freundlich adsorption constants, which can be determined by the linear plot of log qe versus $\log \mathrm{Ce}$.

As it can be seen in table 2. the value of the correlation coefficients, R2 is 0.006 for Lambda cyhalothrin and 0.001 for Diazinon. Thus it comes to the conclusion that the Freudlichmodel does not fit the data of two pesticides as well as the langmuir model does.

Comparison of pesticides adsorption on surface were found in the order diazinon $>$ lambda-cyhalothrin because diazinon due to the electron pumping groups in diazinon which increase the adsorption process thus the stability of diazinon on the surface is higher than other decrease pesticides .

\subsection{Effect of Temperature}

The effect of temperature is shown in figures 7 and 8.The experimental data indicates that the pesticides adsorption decrease with increasing temperature and that agree with thermodynamics properties. The heat of adsorption $\left(\Delta \mathrm{H}^{\circ}\right)$ may be obtained from van't Hoff's equation $[17,18]$.

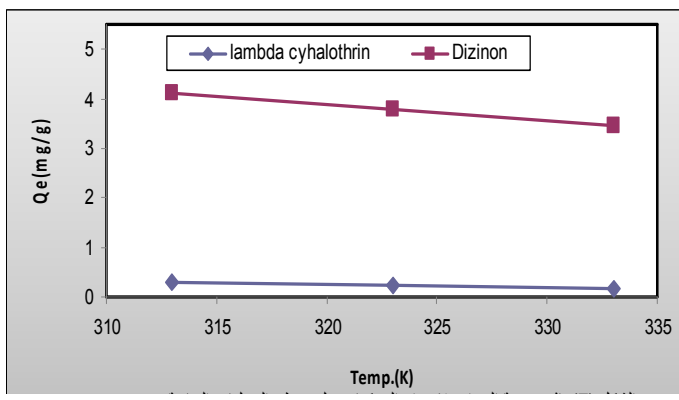

Figure (7). Effect of temperature on the adsorption processes

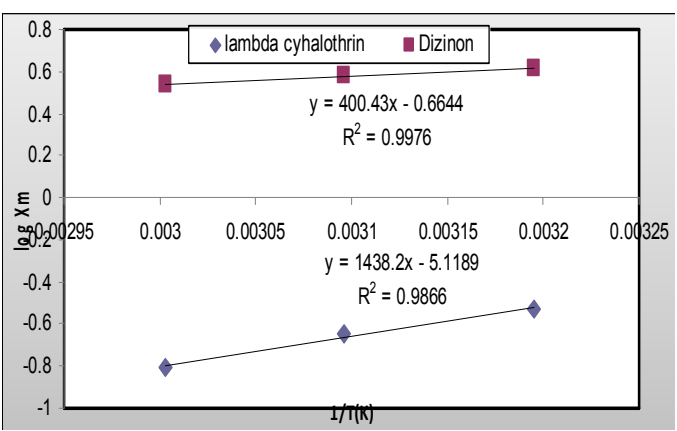

Figure (8). The relationship between the adsorbate quantity and temperature.

Thermddynamic studies

The standard free energy $\left(\Delta G^{\circ}\right)$, enthalpy change $\left(\Delta H^{\circ}\right)$ and entropy change $\left(\Delta S^{\circ}\right)$ thermodynamic parameters were estimatedto evaluate the feasibility of the adsorption process [28,32-35]. The Gibb's free energy change of the process is related to the $\mathrm{Kc}$ by the folloeing equation:

$$
\Delta G^{\circ}=-R T \operatorname{In} K_{c}
$$

Where $\mathrm{T}$ is temperature in $\mathrm{K}$, the ideal gas constant $(8.314 \mathrm{~J} / \mathrm{mol} \mathrm{K})$ and $\mathrm{Kc}$ is the thermodynamic equilibrium constant, which is defined as:

$$
K_{c}=\frac{C \delta}{C e}
$$

Where $C \delta$ is mg of adsorbate adsorbed per liter and $C e$ is the equilibrium concentration of solution, $\mathrm{mg} / \mathrm{L}$. According to thermodynamics, the Gibb;s free energy is also related to the enthalpy change $\left(\Delta H^{\circ}\right)$ and entropy change $\left(\Delta S^{\circ}\right)$ at constant temperature by the van't Hoff equation: 


$$
k_{c}=-\frac{\Delta G^{\circ}}{R T}=-\frac{\Delta H^{\circ}}{R T}+\frac{\Delta S^{\circ}}{R}
$$

In order to determine the thermodynamic parameters. Experiments were carried out at different temperature in the range of $(40,50,60)^{\circ} \mathrm{C}$ (fig.7) the values of enthalpy change $\left(\Delta H^{\circ}\right)$ and entropy change $\left(\Delta S^{\circ}\right)$ were calculated from the slope and intercept of the plot In Kc versus 1/T. the calculated values of thermodynamic parameters are listed in (table 3).

Table (4). Thermodynamic parameters for the adsorption two pesticides on (pp) surface.

\begin{tabular}{llll}
\hline Pesticides & $\begin{array}{l}-\Delta \mathbf{H}^{\circ} \\
(\mathbf{k J} / \mathbf{m o l})\end{array}$ & $\begin{array}{l}-\Delta \mathbf{G}^{\circ} \\
(\mathbf{k J} / \mathbf{m o l})\end{array}$ & $\begin{array}{l}-\mathbf{\Delta} \mathbf{S}^{\circ}(\mathbf{J} / \mathbf{m o l} \\
\mathbf{K})\end{array}$ \\
\hline Diazinon & 7.666 & 3.137 & 34.51 \\
Lambda cyhulothrin & 27.533 & 5.544 & 70.09 \\
\hline
\end{tabular}

For both pesticiedes the valuses of $\left(\Delta H^{\circ}\right)$ are negative, indicating the exothermic nature of the process, which further explain the fact that the adsorption efficiency decreased with the increase of temperature. Negative values of $\left(\Delta S^{\circ}\right)$ indicate a decrease in randomness at the solid/ solution interface during the adsorption process while low value of $\left(\Delta S^{\circ}\right)$ indicates that no remarkable change on entropy occurs. All engative values of $\left(\Delta G^{\circ}\right)$ in the range of 40,50 , $60^{\circ} \mathrm{C}$ indicat the spontaneous nature of the adsorption processes. It was also noted that the change of free energy decreases with increase of temperature. This could be possinle because fewer active sites are available on the surface of adsorbents.

The mangnitude of $\Delta H$ may give an idea about the type of sorption. Two main types of adsorption are physical and chemical. Basically, the heat evolved during physical adsorption is of the same order of magnitude as the heats of condensation, i.e., $2.1-209 \mathrm{~kJ} / \mathrm{mol}$, while the heats of chemisorption generally falls into a range of $80-200 \mathrm{KJ} / \mathrm{mol}$ [22].

\subsection{Effect of Ph}

The $\mathrm{pH}$ is an important factor which controls the adsorption process [19]. The adsorption of both pesticides on the pomegranate peel in different media $(\mathrm{pH}=2-14)$ was studied by using a fixed concentration of the two pesticides at $313 \mathrm{k}$ as shown. in figure e (9). The results indicate at low $\mathrm{pH}$ the pesticides become protonated.

It can be explaind by the following facts. At lower $\mathrm{pH}$ values, $\mathrm{H}+$ in the solution will compete strongly with pesticises for the active sites.therefore, it reduces pesticises binding on the adsorbent surface. When $\mathrm{pH}$ increases, the electrostatic requlsion between pesticises and surface sites and the competing effect of $\mathrm{H}+$ decrease and consequently the pesticises adsorption increases [25]. However at higher $\mathrm{pH}$ values pesticises will be precipitated so the experimental $\mathrm{pH}$ values should be controlled at 2-3.

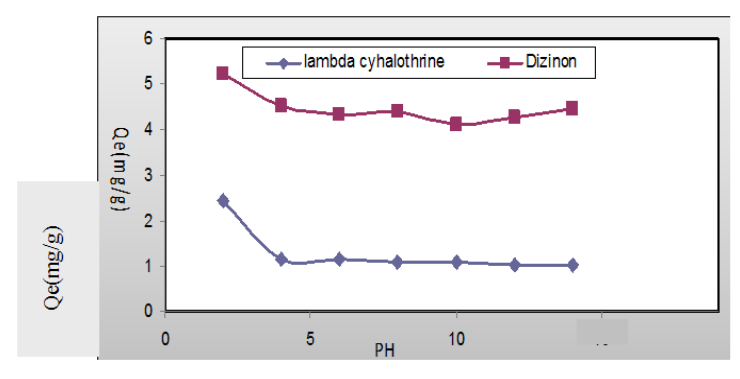

Figure (9). Effect the $\mathrm{pH}$ on the adsorption of two pesticides.

According to Gile's classification the data obtained in this research are followed the type (S2, S4). Also the maximum adsorption time was 30 minute for diazinon and120 minute for lambda cyhatothrin as shown in figure (5) at $313 \mathrm{~K}$ and the maximum weight for the adsorption was $0.2 \mathrm{~g}$ diazinon and $0.05 \mathrm{~g}$ cyhatothrin as in figure (6) and were studied the freundhich and langmuire constants for adsorption process as well as in table 2 [20-21].

\section{Conclusions}

The main object of the present work is to explore the possibility of using pomegranate peel as adsorbents for the cationic pesticides water pollutants.

The experimented data at different temperatures for the pesticides pollutants were fitted to the Langmuir and freundlich isotherms models, and the shape of isotherms was (S-type) on Gile's classification from the thermodynamic values of $\Delta \mathrm{G}, \Delta \mathrm{H}$ and $\Delta \mathrm{S}$ are negative indicating that the process is spontaneous and exothermic the effect of various operating parameters, such as contact time, $\mathrm{pH}$, adsorbent dosage and temperature was estimated.

The thermodynamic functions are very useful if the present results are to be utilized on large scale in dustrail processes.

The authers thank the University of Babylon/ College of science / chemistry department for funding this project.

\section{References}

[1] S. AL- Asheh, F. Banat and L. Abu- Aitah, (Adsorption of phenol using different types of activated bentonites), sep. pur. Tech. 33, 1-10, 2003.

[2] Y. S. HO, (selection of optimum sorption isotherm). J. Carbon, 42, 2115-2116, 2004.

[3] Y. E. Benkli, M. F. Can, M. Turan and M. S. celik (Modification of organo- zealite surface for the removal of reactive azodye in fixed - bed reactors). J. waterResearch, 39, 487-493, 2005.

[4] X. H. Gu, J. T. Zhou, A. L. Zhang and G. F. Liu ( Treatment of hypersaline waste water loaded with phenol by the combination of adsorption and an offline bioregen eration). J. Chem., Technol. And Biotechnol. 83, 1034-1040, 2008.

[5] G. Crini, (Non- conventional low- cost adsorbents for dye removal: A review), J. Bioresour. Technol. 97, 1061-1085, 2006. 
[6] F. R. Rijsberman, (water scarcity: fact or Fiction Agricultural water Management), 80, 5-22, 2006.

[7] Y. S. Ho, (Selection of optimum sorption isotherm J, Carbon., 42, 2115-2116, 2004

[8] L. Lain, L, Guo and C. Guo, (Adsorption of congored from agheous solution on $\mathrm{Ca}$ - bentonite.

[9] M. G. Barrow (physical chemistriy), 5th edition M C GrewHill, New York, 418- 424, 1988.

[10] C. H. Giles and other (studies in adsorption part XI: A system of classification solution Adsorption iso therms Mechanisms and in Measurement of specific surface Area of solids, J. chem.. Soc. 786, 39, 73- 3993, 1960.

[11] C. H. Giles and D. Smith (A General treatment and classication of the solute adsorption isotherm ). J. colloid and Interface science/ 47, 3, 755-765, 1974.

[12] E. Bulut, M. Öza car and I. A. Sengil (Equilibrium and kinetic data and process design for adsorption of congored on bentorite), J. Hazardous materials, 154, 613-622, 2008.

[13] P.W. Atkins (physical chemistry ). 9th edition, oxford University press, 2010.

[14] H. M. F. Freundlich, (uber die Adsorption in losungen), Z. phys. Chem.., 57 (A), 385 (1906).

[15] N. Muhammad, (Adsorption of heavymetals in slow sand filters), 24th edition WEDC conference, Twater treatmeat, Islamabad, Pakistan, pp: 346-349, 1998.

[16] E. H. M. wright, chem., soc., 13, pp. 355-360, (1960).

[17] J. Jkippling, (Adsorption from solution of Non - Eectrolytes), Academic press, Inc. London, 101-168, 256-259, 1956.
[18] L.P. Robert, (Modern methods of chemical analysis), 2nd edition, John wiley and sons, Inc. New York, pp: 54-55, 1976.

[19] T. Santhi, S. Manonmani (Adsorption kinetics of cationic dyes from aqueous solution by Bioadsorption onto activiated in Environmental sanitation 4 (3): 263-271, 2009.

[20] R. AL- Myali and Karem, (Removal of Azure Dyes using Iraqi porcelanite Ro cks and novel PMF polymer), M. Sc. Thesis, college of science, karbala University, 2014.

[21] R. AL- selawy and A. AL- sharify (A study of adsorption ability of Ty (w-6GS) and DB (P- 2BR) dyes from Aqueous solutions by using attapulgite and Bentonite Clays) M. Sc. Thesis, College of science, Babyylon University, 2012.

[22] M.M. Lakouraj, F., Mojerlou , E. N., Zare, Nanogel and superparamagnetic nanocomposite based on sodium alginate for sorption of heavy metal ions. Carbohydrate Polymers, 106, 2014, 34-41.

[23] M. M., Lakouraj, F., Hasanzadeh, E. N., Zare, Nanogel and super-paramagnetic nanocomposite of thiacalix [4] arene functionalized chitosan: Synthesis, characterization an heavy metal sorption, Iran Polym J(2014) 23: 933-945.

[24] E. N., Zare , M. M., Lakouraj, Biodegradable polyaniline/ dextrin conductive nanocomposites: Synthesis, characterization, investigation of antioxidant activity and sorption of heavy metal ions. Iranian Polymer Journal, 23, $2014,257-266$.

[25] Sha Liang, Xueyi Guo, Ningchuan feng, Qinghua Tian Isotherms, Kinetics and thermodynamic studies of adsorption of $\mathrm{Cu} 2+$ from aqueous solution by $\mathrm{Mg} 2+/ \mathrm{K}+$ type orange peel adsorbents, Journal of Hazardous Materials , 174, 2010 , 756-762. 